\title{
CRENÇAS DE APRENDIZAGEM DE LE E SEUS REFLEXOS NA FORMAÇÃO INICIAL DE ALUNOS-PROFESSORES
}

\author{
Darllen Almeida da Silva ${ }^{1}$
}

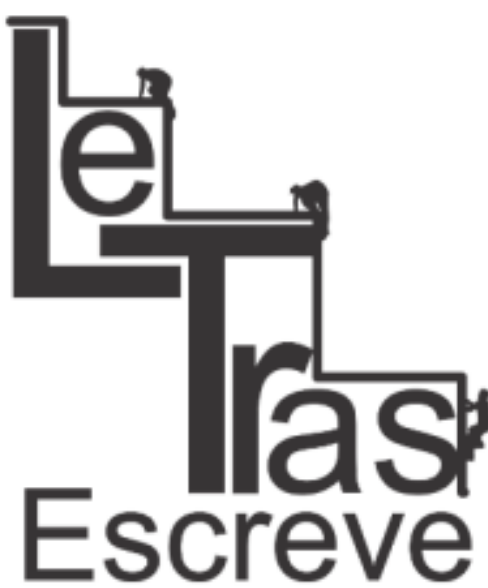

(ISSN 2238-8060)

\begin{abstract}
RESUMO: Muito se tem discutido acerca de como se aprende uma Língua Estrangeira (LE), no entanto, no Brasil, somente a partir da década de 90 os estudos começaram a voltar-se para as crenças de aprendizagem. Há diversas definições para o termo, mas todas convergem para a necessidade de que o aprendiz tenha consciência de suas crenças do que seja aprender e ensinar línguas. Para o aluno em sua formação inicial como professor, isso se torna ainda mais importante, uma vez que permeia tanto a maneira como esse sujeito compreende seu próprio aprendizado, bem como de que forma isso se refletirá em sua prática quando ele estiver em sala de aula. Nesse breve ensaio sobre tão complexa temática busco discutir as diferentes conceituações para o termo crenças e possíveis reflexos na formação inicial de alunos-professores. Trata-se de um conceito complexo que antecede os estudos deste na área da Linguística Aplicada (LA), uma vez que cada um de nós traz em si conceitos pessoais para o termo, entretanto, no que diz respeito aos estudos sobre aprendizagem de LE, vale discutir o que a LA nos trouxe nas últimas décadas através das pesquisas que surgiram na área. Tais pesquisas trouxeram à tona a necessidade de se compreender as concepções do ensinar e aprender uma LE, gerando inclusive outros estudos, por exemplo, os relacionados à autonomia. Ouso dizer que o reconhecimento da existência de crenças relacionadas ao aprendiz e ao professor, retirou das costas deste último o fardo pesado de sua responsabilidade única e exclusiva para o sucesso na aprendizagem de (LE). Isso ocorreu devido ao reconhecimento de que o aprendiz tem papel fundamental nas ações que irão nortear seu próprio aprendizado.

PALAVRAS-CHAVES: Formação inicial. Crenças. Ensino-aprendizagem de LE. Aluno-professor.
\end{abstract}

\section{FOREIGN LANGUAGE LEARNING BELIEFS AND ITS CONSEQUENCES IN THE INITIAL FORMATION OF STUDENTS-TEACHERS}

ABSTRACT: Many things has been discussed about how to learn a Foreign Language (FL), however, in Brazil, only from the 90's the studies begin to turn to the learning beliefs. There are several definitions for the term, but all converge to the learner necessity of being conscious on their beliefs in what is learn and teach languages. For the student in his initial training as a teacher, this becomes even more important, because it permeates both the way this subject understands his own learning, as well as how this will be reflected in his practice when he is in the classroom. In this brief essay on such a complex theme I try to discuss the different asumptions for the term beliefs and possible reflexes in the initial formation of students-teachers.

\footnotetext{
${ }^{1}$ Professora especialista em Língua Inglesa pela Pontifícia Universidade Católica de Minas Gerais - PUC Minas- e atuando na Universidade Federal do Amapá, com foco em Ensino Aprendizagem de LI como Língua Estrangeira. Coordenadora de grupo de pesquisa intitulado: O professor de Língua Inglesa das escolas públicas de ensino médio de Macapá: formação, competências e reflexos no ensino.
}

https://periodicos.unifap.br/index.php/letras

Macapá, v. 6, n. 2, 2o semestre, 2016. 
This is a complex concept that precedes the studies of this area in the area of Applied Linguistics (AL), since each of us carries personal concepts for the term, however, with respect to the studies on learning of $\mathrm{FL}$, It is worth to discuss what AL has brought us in recent decades through the research that has emerged in the area. These researches have brought to the surface the necesity of understand the conceptions of teaching and learning an $\mathrm{FL}$, generating other studies, for example, those related to autonomy. I dare say that the recognition of the existence of apprentice and teacher beliefs has removed that heavy bag of exclusive responsibility for success in FL learning from the teachers back. It was possible to happen because of the recognition that the learner plays a fundamental role in the actions that will guide his own learning.

Keywords: Initial formation. Beliefs. Teaching-learning of a Foreign Language, student-teacher.

\section{Introdução}

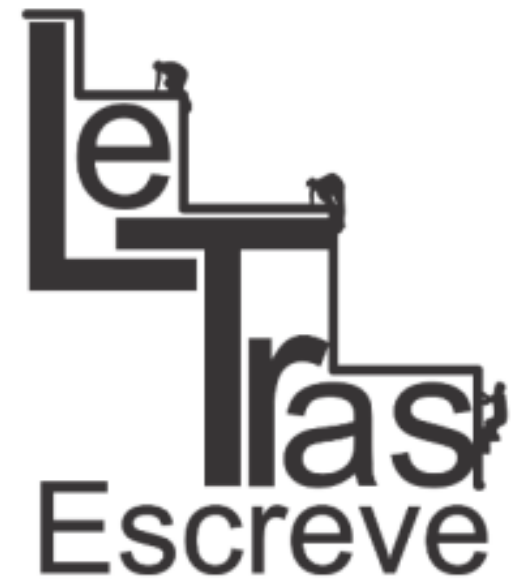

(ISSN 2238-8060)

O presente artigo é resultado das discussões propostas na VI Jornada de Língua Francesa, ocorrida na Universidade Federal do Amapá, no período de 29 a 31 de agosto de 2016. Ao receber o convite para participar da mesa redonda intitulada CRENÇAS NA FORMAÇÃO INICIAL DO PROFESSOR DE LÍNGUAS ESTRANGEIRAS E O DIÁLOGO ENTRE ÁREAS, logo me vieram à mente várias situações em que percebi o quanto as crenças fazem parte das nossas vidas e quanto nos afetam.

Uma das crenças mais comuns, relacionadas ao ensino aprendizagem de língua estrangeira (e aqui me refiro especialmente à língua Inglesa), pude ouvir nos famosos intervalos na sala dos professores: alunos de escolas públicas não aprendem inglês! Ou ainda: Os alunos mal sabem Português, imagine Inglês!

$\mathrm{Na}$ época eu ainda não tinha noção de que falas como essas se tratavam de um vasto campo de estudos da Linguística Aplicada (LA): crenças de ensino e aprendizagem. No entanto, ainda sem adentrar nesse estudo, um questionamento sempre rondava meus pensamentos: Se eles não aprendem, por que ensinamos?

E dessa forma o tema "crenças de aprendizagem" entrava definitivamente no rol de coisas que eu tinha que estudar para que pudesse compreender a importância do meu trabalho como professora de Língua Inglesa. 


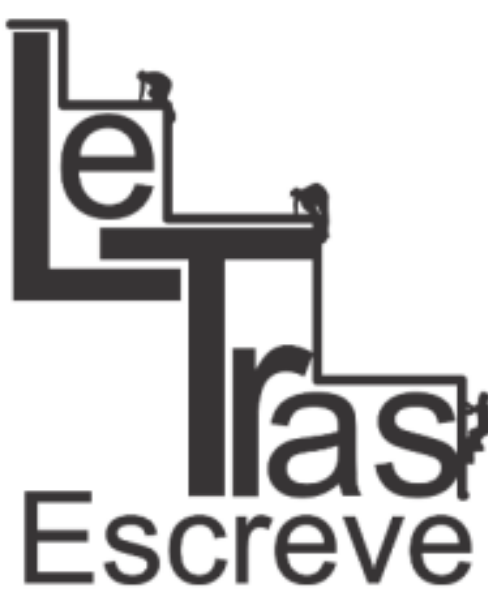

(ISSN 2238-8060)
O presente artigo busca, portanto, refletir sobre 0 assunto, perpassando por conceituações, dentre as muitas que temos na LA, até as discussões sobre os avanços desse estudo e seu reflexo dentro do contexto de aprendizado de Língua Estrangeira de professores em sua formação inicial.

Para tanto, minhas reflexões responderão as seguintes perguntas: 1) Como as crenças podem afetar o aprendizado dos alunos-professores ${ }^{2}$ em sua formação inicial? 2) Em que as crenças podem refletir na prática pedagógica desses alunos? Dessa forma, este artigo está dividido em quatro seções, além desta Introdução e das Considerações finais: a primeira Mitos no aprendizado de Línguas mostra alguns dos principais "mitos" relacionados ao ensino aprendizagem de LE ou L2 ${ }^{3}$; a segunda Crenças: a dificuldade de conceituação evidencia a dificuldade que os pesquisadores tem de conceituar o termo, sendo destacadas as definições de Almeida FiIho (1993), Barcelos (2004) e Cardoso (2002); a terceira A evolução das pesquisas sobre crenças ilustra de forma breve o percurso histórico das pesquisas sobre crenças até o presente; a quarta e última seção Reflexos de crenças de alunos-professores em sua formação inicial expõe de que forma as crenças podem refletir na formação destes e na maneira como compreendem o que é ensinar e aprender uma LE.

\section{Mitos no aprendizado de Línguas}

Antes de iniciar as discussões acerca de crenças, cabe analisar algumas "falas" comuns relacionadas ao ensino aprendizagem de Língua Estrangeira e como elas podem se refletir na prática do professor. Considero então o estudo de Mclaughlin (1992) o qual se propõe a analisar alguns "mitos e conceitos errados" ${ }^{4}$ sobre como as

\footnotetext{
${ }^{2}$ Refiro-me ao termo "alunos-professores" para designar aqueles alunos que já atuam na docência, ainda que não tenham a formação inicial concluída.

${ }^{3} \mathrm{LE}$ se refere ao estudo de uma língua como língua estrangeira e L2 se refere ao estudo de uma segunda língua.

${ }^{4}$ Tradução minha, retirada do título do artigo: "Myths and Misconceptions about second
} 


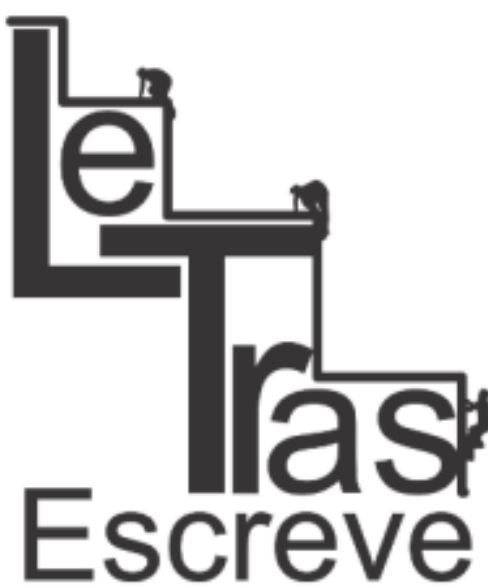

(ISSN 2238-8060) crianças aprendem uma segunda língua, no presente artigo destaco os que considero comuns no contexto brasileiro.

O primeiro "mito" destacado diz o seguinte: "crianças aprendem segunda língua mais rapidamente e facilmente". Não é incomum ouvirmos isso no dia-a-dia, como forma de justificar muitas vezes as dificuldades que adultos encontram na aquisição de língua. Segundo o citado autor, isso se deve ao argumento de que o cérebro das crianças é mais flexível (Lenneberg, 1967; Penfield \&Roberts, 1959. Apud Mclaughlin, 1992). Assim, parece-nos haver uma vantagem biológica, a qual o professor não teria domínio, ou como agir em relação a outras faixas etárias. No entanto, Mclaughlin, reforça que essas diferenças de aprendizado podem ocorrer devido a questões psicológicas e sociais que vão além das biológicas.

Sobre esse "mito", o pesquisador acrescenta que o papel do professor é estar sensível às situações de aprendizado, não esperando "resultados milagrosos" no aprendizado de crianças, bem como não fazendo comparações entre aprendizados. Depreende-se então que o melhor caminho é considerar que há diferentes estilos de aprendizagem, os quais independem de questões puramente biológicas.

Outro "mito" diz que "quanto mais jovem, maior a habilidade de adquirir segunda língua". Mclaughlin diz que esse mito está relacionado ao "melhor momento" para iniciar a aprendizagem de uma língua, destacando que, evidentemente, em sua opinião aprender uma segunda língua simultaneamente a língua materna parece ser uma ótima opção. No entanto, o autor apresenta resultados de um estudo sobre crianças britânicas aprendendo francês na escola, no qual após cinco anos de exposição à língua, constatou-se que crianças que iniciaram seus estudos em idade mais avançada obtiveram melhor resultado nos testes propostos.

Uma vez que se tratava de um contexto formal de ensino, vol-

language learning: what every teacher needs to unlearn"

https://periodicos.unifap.br/index.php/letras

Macapá, v. 6, n. 2, 2ㅇ semestre, 2016. 


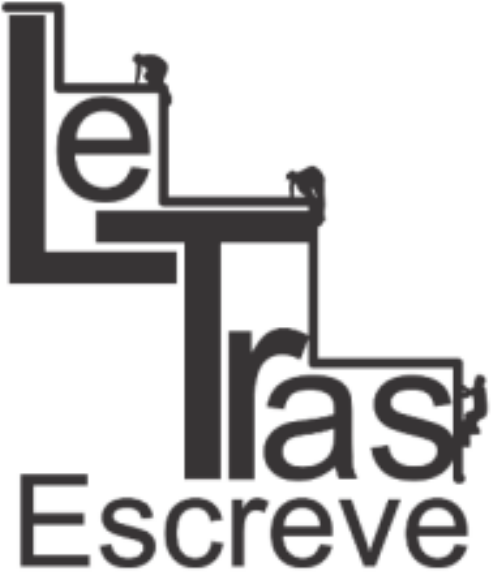

(ISSN 2238-8060)

tado à estrutura da língua, concluiu-se que as crianças mais velhas tinham a habilidade de compreender melhor uma abordagem instrucional do que as crianças mais jovens.

Dessa forma, compreende-se que não há como concluir que quanto mais cedo for iniciado o ensino de uma LE ou segunda língua maior será a chance de sucesso. Crianças podem ter a seu favor o aspecto fisiológico, como o aparelho fonador em formação e apto a absorver novos sons, o que fatalmente contribuirá para a habilidade oral e de escuta, mas que não garante que será "fácil" o desenvolvimento das demais competências relacionadas à aquisição de linguagem.

Outro "mito" apresentado no estudo de Mclaughlin diz que "todas as crianças aprendem uma segunda língua da mesma maneira". É importante destacar que, segundo o autor, ainda que não admitam, os professores acreditam nesse "mito". Entretanto, há que se considerar o aspecto cultural, o qual determina o estilo e as funções da linguagem. Estudos apresentados pelo autor demonstram que crianças de diferentes grupos sociais tendem a utilizar a língua de forma mais indutiva, sendo que as acepções devem ser inferidas pelo contexto.

Mclaughlin destaca ainda que a classe social da criança também se reflete nos estilos de linguagem utilizados. $O$ que $O$ autor tenta demonstrar através disso é que se há condicionantes que dividem os grupos sociais, isso se refletirá na língua e na maneira como é usada e assim, consequentemente, na maneira como elas aprendem a língua. Logo, considerar que o aprendizado ocorre da mesma forma para todos e assim as atividades propostas devem ser generalizadas pode levar o professor a não selecionar adequadamente suas atividades e sua abordagem de ensinar.

Dessa forma, cabe ao professor atentar para os aspectos culturais e a individualidade de seus alunos. Assim, conclui o autor que um ensino efetivo deve levar em consideração os "valores culturais natos" e também deve buscar "desenvolver nas crianças uma atitude emocional positiva".

https://periodicos.unifap.br/index.php/letras

Macapá, v. 6, n. 2, 20 semestre, 2016. 


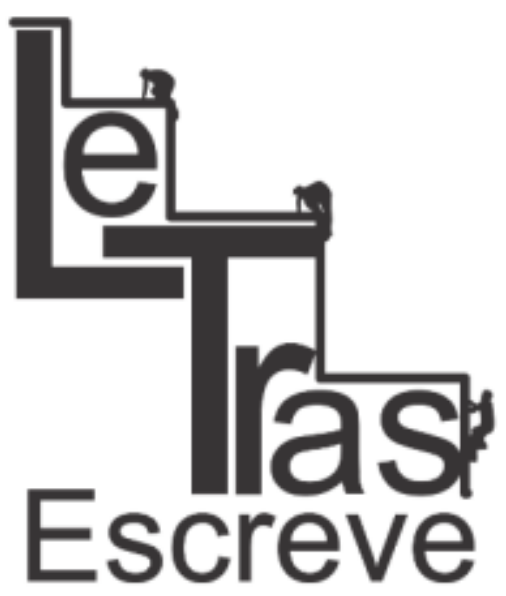

(ISSN 2238-8060)

Ainda que os "mitos" apresentados no citado artigo sejam relacionados ao aprendizado de crianças e em contextos de ensino de segunda língua, eles retratam muito bem algumas falácias relacionadas ao ensino de LE no Brasil, vindo a contribuir positivamente nas discussões propostas.

No Brasil, vários trabalhos estão relacionados às crenças de aprendizagem em diferentes contextos: crenças de alunos de ensino médio, de crianças, de professores em formação, de professores em ação. Elas variaram na mesma medida que as definições e terminologias também foram surgindo. Assim, cabe destacar que a discussão proposta leva a um desses conceitos passíveis de análise, ou seja, relaciona-se ao professor que se encontra em processo de formação. As discussões acerca disso serão retomadas no tópico 4: Reflexos de crenças de alunos professores em sua formação inicial.

\section{Crenças: a dificuldade de conceituação}

Neste tópico busco discutir alguns conceitos sobre crenças, uma vez que a visão acerca do que se define como crenças de aprendizagem sugere diferentes maneiras de compreendê-las e estudá-las. Barcellos (2004, p. 129) nos atenta para o fato de que "o conceito de crenças não é específico da LA". Segundo a autora, outras áreas como a sociologia, antropologia, educação e a filosofia demonstram a preocupação como o que é "verdadeiro ou falso". Assim, conclui-se que não há como se obter um conceito uníssono.

No que se refere à Linguística Aplicada, inicialmente, é válido dizer que Hosenfeld (1978, apud Barcelos 2004) foi o primeiro a usar o termo "mini teorias de aprendizagem" referindo-se ao conhecimento implícito dos alunos. Segundo Barcellos (2004, p.127), apesar de Hosenfeld não ter usado o termo crenças, já foi possível considerar a importância do "conhecimento tácito dos alunos", o que abriu portas para mais estudos na área da linguagem.

No Brasil, somente a partir da década de 1990 é que os estudos intensificaram-se e destaco aqui os conceitos de Almeida Filho 
(1993), Barcelos (2004 e 2007) e Cardoso (2002).

Iniciando as discussões sobre os diferentes conceitos e nomenclaturas de crenças, cito Almeida filho, o qual utiliza o termo "abordagem ou cultura de aprender" para referir-se à:

Maneiras de estudar e de se preparar para o uso da língua-alvo consideradas como 'normais' pelo aluno e típicas de sua região, etnia, classe social ou grupo familiar, restrito em alguns casos, transmitidas como tradição, através do tempo, de uma forma naturalizada, subconsciente e implícita. (ALMEIDA FILHO, 1993, P.13)

Observa-se, portanto, que para o autor a linguagem está intrinsicamente ligada à forma como o aluno percebe seu aprendizado e o considera adequado ao seu contexto social, perpetuando assim,

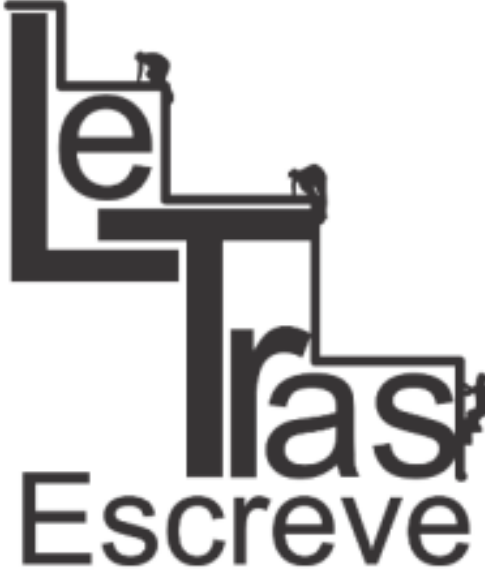

(ISSN 2238-8060) a forma como ele se dá. Observa-se que Almeida Filho nos fala que essa forma de aprender é "naturalizada, subconsciente e implícita", ou seja, ela parte do aprendiz e de como ele acredita ser a melhor forma de aprender uma língua.

Barcellos (2004) já utiliza o termo crenças ao se referir às "ideias, opiniões e pressupostos que alunos e professores têm a respeito dos processos de ensino aprendizagem de línguas". Dessa maneira, observa-se que a autora compreende que as crenças partem tanto dos aprendizes quando dos professores, o que obviamente se reflete na maneira com que compreendem ser mais eficaz 0 aprendizado de uma língua. Isso porque, segundo a autora, esse processo ocorre a partir das próprias experiências desses sujeitos.

Cardoso (2002, p.21 apud Almeida Filho ${ }^{5}$ ) utiliza o termo "imaginário" ao se referir ao "conjunto de imagens que nos guiam para entender o processo de ensinar, no caso do professor, e de aprender, no caso do aluno". Para a autora:

No imaginário situa-se a raiz do implícito, lugar recôndito que guarda as crenças, as sensações, as intuições sobre o processo de aprender e de ensi-

\footnotetext{
${ }^{5}$ Cardoso cita uma fala pessoal de Almeida filho em sua tese de dissertação.
} 
nar que nos orientam e nos levam a agir como aluno e como professor. O imaginário é, pois, constituído ao longo da vida pessoal e profissional do professor. (CARDOSO, 2002, p.21)

Em outras palavras, o imaginário é o que se entende como a forma de ensinar e aprender uma língua. Considero esse um termo muito apropriado, uma vez que nos remete às imagens e de que forma elas agem na compreensão do processo de aprendizagem.

Existem muitos outros termos e definições, no entanto, destaco que utilizo nesse artigo o termo crenças, por comungar da definição de Barcelos (2004) apresentada anteriormente. Ainda segundo essa autora, diante de tantas definições é possível pontuar que "as crenças se referem à natureza da linguagem e ao ensino/aprendizagem de línguas".

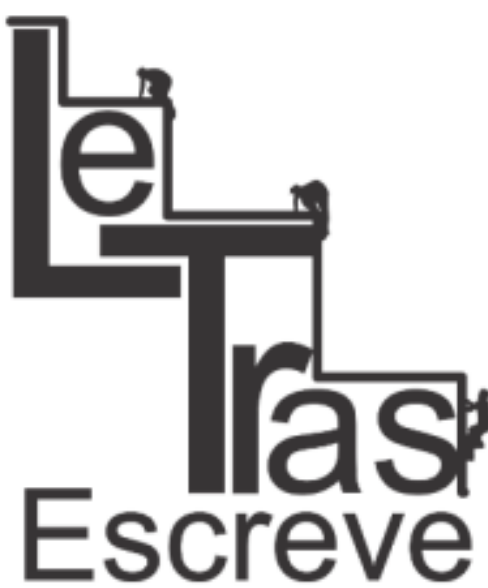

(ISSN 2238-8060)

Ela aponta também para o caráter social das crenças, colocando-as como "ferramentas que ajudam os alunos a interpretar suas experiências" (Barcelos, 2004, p.132). Compreende-se, portanto, que crenças correspondem ao próprio conceito que cada indivíduo possui sobre o ensino/aprendizagem de uma Língua Estrangeira, pautados em suas experiências e na interação social. Crenças são, por conseguinte, dinâmicas, ressalta a autora.

\section{A evolução das pesquisas sobre crenças}

As pesquisas relacionadas a crenças tem ganhado espaço e são cada vez mais frequentes, pois proporcionam um (re)pensar sobre como concebemos aprender e ensinar uma língua.

Barcelos (2004) destaca que as pesquisas sobre o tema, se dividem em três momentos: 0 1 momento refere-se ao período inicial (1990-1995), o 2o momento diz respeito ao período de desenvolvimento e consolidação (1996-2001) e o 3ํmomento é o período de expansão (2002 até o presente)

No 1ํmento, Barcelos (2007, p.31) destaca Leffa (1991, apud Barcelos, 2007). Segundo a autora "embora não tenha utilizado 


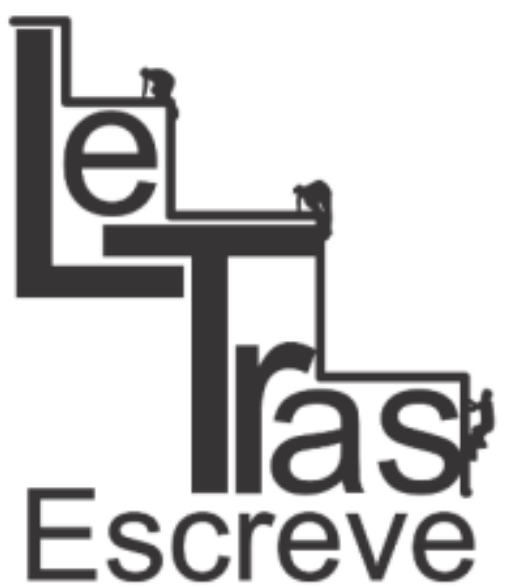

(ISSN 2238-8060)

o termo crença e sim concepções, foi pioneiro por reconhecer que os alunos possuem crenças sobre aprendizagem de línguas". O estudo de Leffa mostrou que os alunos pesquisados não tinham nenhuma estratégia de aprendizagem, pois acreditavam que o estudo de língua inglesa se limitava a "decorar" vocabulário e fazer tradução.

Barcelos (2004) destaca que nesse primeiro momento eram aplicados questionários fechados, os quais traziam à tona afirmações abstratas e caracterizavam o aluno como inadequado e assim, "apesar de o foco ser as perspectivas dos aprendizes, os mesmos são criticados por possuírem determinadas crenças" (Barcelos, 2004, p.134). A autora ainda destaca que as pesquisas ignoravam o contexto, e segundo ela, "em resumo, a pesquisa das crenças, nesse primeiro momento, ignora a perspectiva do aluno". Sobre esse primeiro momento de estudo de crenças, a autora conclui:

\begin{abstract}
"Em resumo, o período inicial da pesquisa de crenças no Brasil [ ] foi caracterizado por poucos estudos - apenas três dissertações e uma tese. Alguns desses trabalhos procuravam mostrar, ainda que de forma periférica, um fenômeno ao qual, naquele período, não se dava o nome de crenças no Brasil, mas de mitos, representações e concepções". (BARCELOS, 2007, p.35)
\end{abstract}

No $2^{\circ}$ momento, a principal característica diz respeito à autonomia do ensino, pois nesse período há uma aproximação das pesquisas com as estratégias de aprendizagem. Barcelos (2004, p. 136) aponta para o fato de que nessa fase há "uma preocupação nesses estudos com uma noção prescritiva de crenças", para ela isso se deve ao fato de se pensar em quais crenças são erradas e quais são corretas, bem como quais se tornam "obstáculos à autonomia".

Nesse período ela destaca que já se pode vislumbrar um campo de estudos sobre diferentes características, devido às dissertações defendidas em várias universidades brasileiras.

A autora destaca algumas dessas características: foco nas culturas de aprender, ensinar e avaliar; contexto do ensino médio; estudos sobre crenças de professores; crenças específicas, estudos

https://periodicos.unifap.br/index.php/letras

Macapá, v. 6, n. 2, 20 semestre, 2016. 


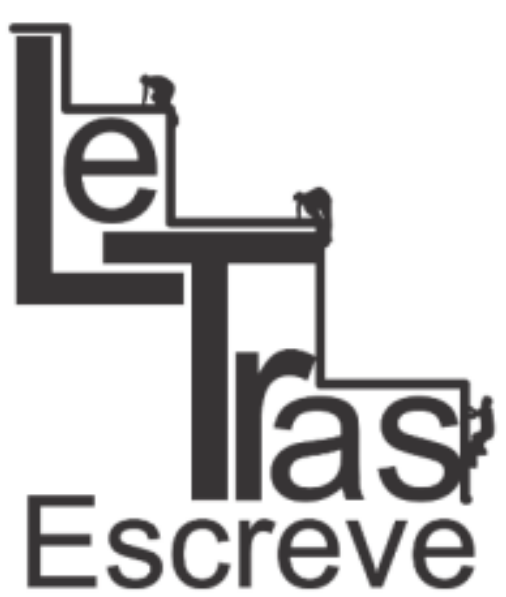

(ISSN 2238-8060)

que utilizaram o questionário BALLI (Beliefs about Language Learning Inventory $)^{6} \mathrm{e}$ crenças a respeito de outras línguas estrangeiras.

Observa-se, portanto, que esse é um período de consolidação dos estudos sobre crenças, no qual se pôde perceber o leque de perspectivas que as pesquisas poderiam abrir, reforçando o caráter de compreender melhor o "porquê" e o "como" aprendemos e ensinamos uma Língua Estrangeira.

O $3^{\circ}$ momento apresenta uma "maior pluralidade de metodologia e de percepções diferentes sobre como fazer pesquisa a respeito de crenças" (Barcelos, 2004, p.137). A autora agrupa os estudos desse período de forma que se possa vislumbrar melhor o panorama das pesquisas nesse período (Barcelos, 2007, p. 45):

a. Estudos de crenças dentro da cultura de aprender e avaliar;

b. Estudos de crenças sobre outras línguas estrangeiras;

c. Estudos de crenças como parte de outros conceitos;

d. Estudos de crenças específicas.

Em seu artigo, Barcelos faz um panorama sobre as mais importantes contribuições dentro desses grupos, as quais não serão expostas no presente artigo. Contudo, vale destacar que os estudos sobre crenças específicas traz a possibilidade de se compreender melhor alguns pontos interessantes, os quais considero essenciais, pois respondem a questionamentos muito comuns no dia a dia do professor atuante. Destaco entre crenças específicas os estudos de crenças sobre a gramática, aprendizagem de inglês em escolas públicas, o bom aprendiz, correção e erros e crenças de leitura e escrita.

Assim, dentro dessa perspectiva de que as pesquisas atualmente buscam focar em grupos específicos, o tópico seguinte, o qual apresenta alguns reflexos de crenças de alunos-professores nas atividades de docência destes, parece contribuir para as discussões acerca da necessidade de se compreender melhor como as

\footnotetext{
${ }^{6}$ Trata-se de um tipo de questionário desenvolvido por Horwitz (1985) que faz um inventário das crenças subdividindo-as em cinco categorias: 1 - Aptidão de língua estrangeira; 2 - Dificuldades de aprendizagem; 3 - Aprendizagem e estratégias de comunicação; 4 Natureza da aprendizagem na língua e 5 - Motivação.
}

https://periodicos.unifap.br/index.php/letras

Macapá, v. 6, n. 2, 20 semestre, 2016. 
crenças se processam e de que forma elas agem sobre grupos específicos.

\section{Reflexos de crenças de alunos-professores em sua formação inicial}

Considerando as diversas definições existentes sobre crenças, bem como as apresentadas nesse artigo, a análise sobre o reflexo delas em alunos-professores se faz importante, uma vez que recaem no modo como aprendem e ensinam uma língua estrangeira.

Abrahão (2004) ressalta que:

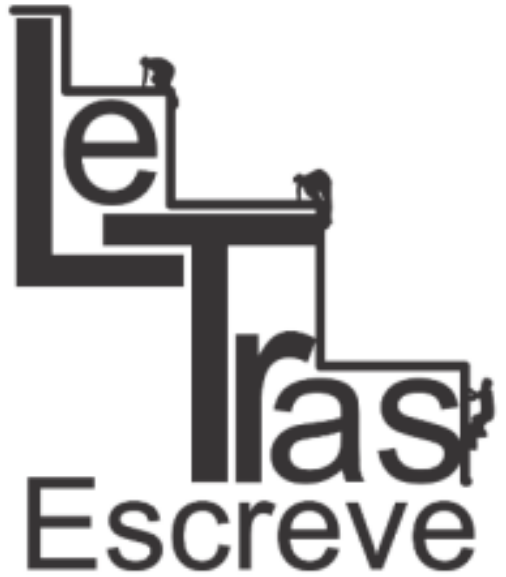

(ISSN 2238-8060)

É consenso entre teóricos e formadores que professores trazem para seus cursos de formação e para as suas salas de aula crenças, pressupostos, valores, conhecimentos e experiências, adquiridos ao longo de suas vidas, e que estes funcionam como filtros de insumos recebidos por meio da exposição às teorias e práticas. Isto quer dizer que, ao entrarem em contato com o conhecimento teóricoprático nos cursos de formação, cada professor ou aluno-professor faz uma leitura particular, o que traz reflexos para a construção de sua prática pedagógica. (ABRAHÃO,2004 . p. 131)

Assim, tendo em vista tal perspectiva, diversos estudos surgiram, analisando de que forma as crenças dos professores em formação seriam determinantes em suas ações em sala de aula e embora diferentes, esses estudos se assemelham ao compreender que as experiências dos professores devem ser levadas em consideração quando em sua formação, pois como afirma Abrahão (2004, p.132), "o professor não é mais visto como 'tábula rasa' que pode simplesmente ser 'treinado' para atingir conhecimentos desejados". Antes de tudo ele deve ser visto como um ser social, que vivenciou experiências, inclusive de aprender e que, portanto, traz suas próprias crenças do como e porquê ensinar línguas.

Apesar de as pesquisas apontarem para o reconhecimento de que o professor em formação tem suas crenças, é importante frisar que este, por sua vez, em muitos casos não tem consciência de tais

https://periodicos.unifap.br/index.php/letras

Macapá, v. 6, n. 2, 20 semestre, 2016. 
crenças. Segundo Abrahão (2004):

No caso da formação pré-serviço nos cursos de Letras, o aluno-professor, entre todas as outras experiências de vida, traz uma experiência rica como aprendiz, as vezes já como professor, além de uma gama de conhecimentos teóricos adquirida nos primeiros anos do curso universitário. No entanto, poucos tiveram a oportunidade de buscar uma explicitação das crenças, pressupostos e conhecimentos que têm sobre o que está envolvido no processo ensino-aprendizagem da língua que vão ensinar. (ABRAHÃO, 2004, p.132)

Observa-se, portanto, que há necessidade de que os professores em formação possam refletir sobre as crenças que permeiam o seu próprio agir, pois se os cursos de formação atentarem para essa reflexão, entregarão à sociedade profissionais mais conscientes de suas ações, bem como determinadas falácias, resultantes de crenças enraizadas, tais como as apresentadas na introdução deste artigo, possam ser evitadas e a perpetuação delas estancada.

\section{Considerações finais}

No presente estudo foram discutidos de forma breve alguns aspectos relacionados a um dos estudos mais eminentes na área da Linguística Aplicada: as crenças de ensino aprendizagem. Inicialmente, buscou-se discutir algumas crenças comuns relacionadas ao ensino aprendizagem de línguas, como forma de iniciar as reflexões acerca do tema.

Em seguida o estudo propôs compreender a seara de terminologias para o tema, sendo escolhida aqui para esse trabalho a terminologia "crenças", uma vez que comungo da definição de Barcelos (2004) apresentado no corpo do trabalho.

Após essas discussões e ainda embasando-se em Barcelos foi levantado um panorama das pesquisas no Brasil, analisando-se de que forma elas foram consolidando a importância dos estudos sobre crenças.

Por fim, este estudo buscou refletir sobre as crenças e seus 


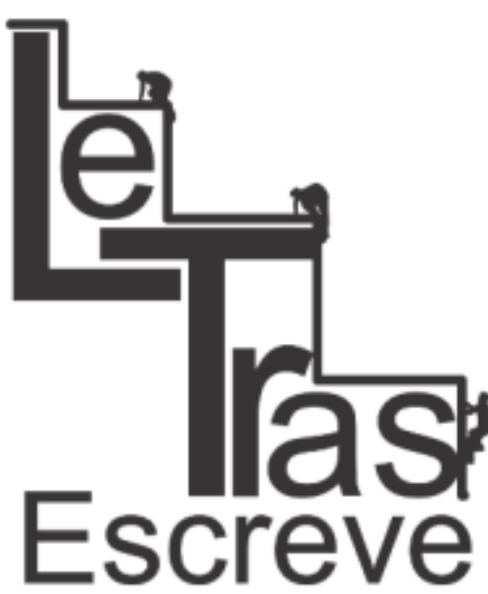

(ISSN 2238-8060) reflexos na formação inicial de alunos-professores, pois considera-se que o reconhecimento de que estes trazem sua carga de experiências e que tais experiências geram crenças que muitas vezes se perpetuam e se refletem em suas práticas docentes, pode proporcionar uma formação mais crítica desse professor.

Retomo então as perguntas que nortearam minhas reflexões/discussões. No que diz respeito ao primeiro questionamento: como as crenças podem afetar o aprendizado de alunos-professores em sua formação inicial? ressalta-se que uma vez internalizadas certas crenças sobre como aprender uma LE, o aluno-professor pode não refletir sobre sua própria prática, agindo então como mero repetidor de abordagens de ensino.

Corrobra com tal afirmação Abrahão (2004) quando diz que quando o professor não desenvolve sua competência aplicada para que seja capaz de compreender como ensina e porque ensina de tal maneira, "ele atua utilizando o imaginário, as representações do que adquiriu através de percepções do seu tempo de estudante para orientar seu modo de ensinar" (Abrahão, 2004, p.21)

Compreendendo que para a autora o termo "imaginário" corresponde ao termo "crenças", utilizado nesse artigo, observasse então que as crenças agem diretamente sobre a forma com que o professor direcionará suas atividades, assim a formação inicial desse professor pode e deve levá-lo a compreender as crenças que permeiam o seu agir profissional.

Assim, respondo também ao segundo questionamento, o qual está relacionado ao reflexo das crenças na prática pedagógica desses alunos-professores, pois como dito anteriormente, a consciência de que existem crenças, muitas vezes já internalizadas sobre como ensinar e aprender uma LE, é de suma importância para que o professor possa compreender suas práticas e principalmente, ser capaz de modificá-las, caso observe que estas não contribuem positivamente para ao aprendizado daqueles que estão sob sua guarda, no que se refere a aprender uma LE.

As discussões aqui propostas, longe de cessar qualquer as- 
sunto relacionado a crenças de aprendizagem, buscaram corroborar com a necessidade de que outras pesquisas e discussões sejam levantadas para que mais e mais professores se perguntem por que ensinam como ensinam, reflitam sobre suas práticas e jamais considerem que crenças internalizadas e perpetuadas possam servir como parâmetro para suas ações.

\section{Referências}

ABRAHÃO, M.H Vieira. Crenças, pressupostos e conhecimentos de alunos professores de língua estrangeira e sua formação inicial. In Prática de ensino de língua estrangeira. Campinas, SP: Pontes Editores, 2004.

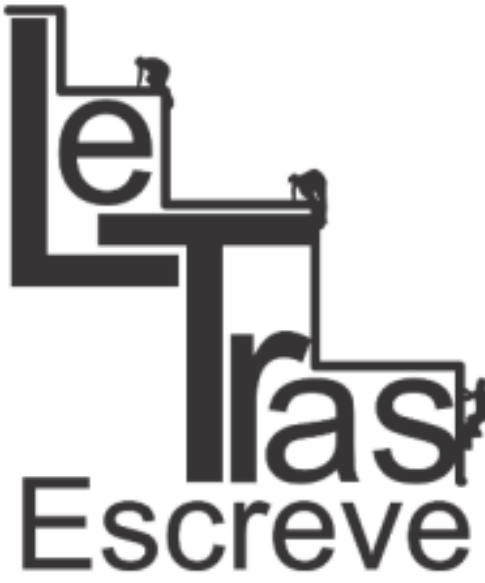

(ISSN 2238-8060)

ALMEIDA FILHO, J.C.P. Dimensões comunicativas no ensino de línguas. Campinas, SP: Pontes Editores, 1993.

BARCELOS, A.M.F. Crenças sobre aprendizagem de línguas, linguística aplicada e ensino de línguas. In: Linguagem \& Ensino, v.7, №1, p.123-156, 2004.

. Crenças sobre ensino e aprendizagem de línguas: reflexões

de uma década de pesquisa no Brasil. In: M;L Ortiz Alvarez; K. A da Silva (org.). Linguística Aplicada: Múltiplos olhares. Campinas: Pontes, 2007, v. , p. 27-69.

CARDOSO, R.C.T. O imaginário do comunicativismo entre professores de língua estrangeira / Inglês (e sua confrontação com teoria externa). Tese (Doutorado em Letras - Filologia e Lingüística Portuguesa), Faculdade de Ciências e Letras, Universidade Estadual Paulista, Assis, 2002.

MCLAUGHLIN, Barry. Myths and misconceptions about second language learning: what every teacher needs to unlearn. University of California, Santa Cruz, 1992.

Recebido em 29 de novembro de 2016 Aprovado em 15 de janeiro de 2017 